\title{
"An Inventory Model of Repairable Items with Exponential Deterioration and Linear Demand Rate"
}

\author{
U. B. Gothi ${ }^{1}$, Malav Joshi ${ }^{2}$, Kirtan Parmar $^{3}$ \\ ${ }^{1}$ Head \& Associate Prof.,Dept. of Statistics, St. Xavier's College (Autonomous), Ahmedabad, Gujarat, India. \\ ${ }^{2}$ Research Scholar, Dept. of Statistics, St. Xavier's College (Autonomous), Ahmedabad, Gujarat, India. \\ ${ }^{3}$ Assitant Prof., Dept. of Statistics, St. Xavier's College (Autonomous), Ahmedabad, Gujarat, India.
}

\begin{abstract}
In this paper an inventory model for deteriorating and repairable itemsis developed with linear demand. An Exponential distribution is used to represent the distribution of time for deterioration.In the model considered here, shortages are allowed to occur and defective items can be repaired. The model is solved analytically to obtain the optimal solution of the problem. The derived model is illustrated by a numerical example and its sensitivity analysis is carried out.
\end{abstract}

\section{Introduction}

Deterioration means damage, spoilage, dryness, vaporization, etc. It is defined as decay or damage such that the item cannot be used for its original purposes. The effect of deterioration is very important in many inventory systems. The pioneering work of Harris [7] inventory models are being treated by mathematical techniques. He developed the simplest inventory model, the Economic Order Quantity (EOQ) model which was later popularized by Wilson [24]. Relaxation of some assumptions in the formulation of the EOQ model led to the development of other inventory models that effectively tackles several other inventory problems occurring in day-to-day life. Inventory of deteriorating items was first studied by Whitin [25] where he considered the deterioration of fashion goods at the end of prescribed storage period. Ghare and Schrader [5] extended the classical EOQ formula to include exponential decay, wherein a constant fraction of on hand inventory is assumed to be lost due to deterioration.

Datta, T. K. and Pal, A. K. [4]gave order level inventory system with power demand pattern for items with variable rate of deterioration. Mandal, B. N. and Ghosh, A. K. [14] wrote a note on an inventory model with different demand rates during stock in and stock out period. Mandal, B. N. and Pal A. K. [15] have given order level inventory system for perishable items with power demand pattern. Teng, J. T. [21] has worked on model with linear trend in demand.

Manna and Chiang [13] developed an EPQ model for deteriorating items with ramp type demand. Teng and Chang [22] considered the economic production quantity model for deteriorating items with stock level and selling price dependent demand. Jain et al. [8] developed an economic production quantity model with shortages by incorporating the deterioration effect and stock dependent demand rate. Roy and Chaudhary [17] developed two production rates inventory model for deteriorating items when the demand rate was assumed to be stock dependent. In the research of Sana et al. [18] shortages are allowed to occur at the end of a cycle. With the consideration of time varying demand and constant deteriorating rate, the optimal production inventory policy was studied. Raman Patel [16] developed a production inventory model for deteriorating items following Weibull distribution with price and quantity dependent demand and varying holding cost with shortages.

Both Skouri and Papachristos [20] and Chen et al. [2] developed a production inventory model in which the shortages are allowed at the beginning of a cycle. In contrast,Manna and Chaudhari [12] have allowed shortages to occur at the end of each cycle. Goyal[6] deals with production inventory problem of a product with time varying demand, production and deterioration rates in which the shortages occur at the beginning of the cycle.

There are four synonyms of reuse according to Thierry et al. [23]. They are: Direct Reuse, Repair, Recycling and Remanufacturing. Schrady[19] was the first to consider reuse in a deterministic model.Recently, Mabini et al. [11] extended Schrady's model to consider stock-out service level constraints and multi-item system sharing the same repair facility. In the policy, expressions for the optimal control parameter values were derived. Koh[10] developed a joint EOQ and EPQ model in which the stationary demand can be satisfied by recycled products and newly purchased products. The model assumes a fixed proportion of the used products that are collected from the customers.

Recently, Bhojak and Gothi [1] have developed inventory models for ameliorating and deteriorating items with time dependent demand and IHC. Kirtan Parmar and Gothi [9] have developed an EPQ model of deteriorating items using three parameter Weibull distribution with constant production rate and time varying 
holding cost.Devyani Chatterji and Gothi [3] have developed three-parametric Weibully deteriorated EOQ model with price dependent demand and shortages under fully backlogged condition.

R. K. Yadav and Rajeev Kumar [26] developed an inventory model for deteriorating and repairable items with linear demand.Here, we have tried to redevelop the same model and corrected most of the results.

\section{Notations}

The mathematical model in this paper is developed using the following notations:

1. $\mathrm{k} \quad$ : Production rate (units/unit time).

2. D : Demand rate.

3. $\theta(\mathrm{t}) \quad:$ The deterioration rate (units/unit time).

4. b :The decreasing rate of the demand (units/unit time).

5. c : Fraction of defective product.

6. $\mathrm{r} \quad$ :Fraction of stock-out demand sales lost due to some stock-out demands. $(0<\mathrm{r}<1)$

7. $Q(t)$ :The instantaneous state of the inventory level at any time $t(0 \leq t \leq T)$.

8. $Q_{1} \quad$ : The maximum inventory level of the product.

9. $\mathrm{Q}_{2}$ : The maximum inventory level during shortage period.

10. A : Ordering cost per order.

10. $C_{h}$ :Inventory holding cost per unit per unit time.

11. $\mathrm{C}_{\mathrm{d}}$ : Deterioration cost per unit per unit time.

12. $\mathrm{C}_{\mathrm{s}}$ :Shortage costper unit.

13. $\mathrm{C}_{\mathrm{p}}$ : The penalty cost of a lost sale including lost profit (unit time).

14. Pc : Purchase cost per unit.

15. TC : The average total cost for the time period $[0, \mathrm{~T}]$.

\section{Basic Assumptions}

The model is derived under the following assumptions

1. The inventory system deals with single item.

2. The production rate is finite and constant, which is larger than the demand rate and is unaffected by the lot size.

3. Once a unit of the product is produced, it is available to meet the demand.

4. Once the production is started the product starts being deteriorated.

5. The annual demand rate is a linear function of time and it is $\mathrm{D}=\alpha+\beta \mathrm{t} . \quad(\alpha, \beta>0)$.

6.Shortages are allowed and completely backlogged.

7. Replenishment rate is infinite and instantaneous.

8. All defective products can be repaired and reused.

9. The second and higher powers of $\theta, b$ and care neglected in the analysis of the derived model.

10. Total inventory cost is a real, continuous function which is convex to the origin.

\section{Mathematical Model And Analysis}

Here, we consider a single commodity deterministic production inventory model with a time dependentlinear demand rate. The distribution of the time to deteriorate is random variable following the exponential distribution. The probability density function for exponential distribution is given by

$$
\mathrm{f}(\mathrm{t})=\theta \mathrm{e}^{-\theta \mathrm{t}} \quad ;(\mathrm{t}>0 \text { and } 0<\theta<1)
$$

The instantaneous rate of deterioration $\theta(t)$ of the non-deteriorated inventory at time $t$ can be obtained from $\theta(\mathrm{t})=\frac{\mathrm{f}(\mathrm{t})}{1-\mathrm{F}(\mathrm{t})}$, where $\mathrm{F}(\mathrm{t})=1-\mathrm{e}^{-\theta \mathrm{t}}$ is the cumulative distribution function for the exponential distribution.Thus, the instantaneous rate of deterioration of the on-hand inventory is $\theta(t)=\theta$. The probability density function represents the distribution of the time to deteriorate which may have a decreasing, constant or increasing rate of deterioration.

Initially, inventory level is zero. At time $\mathrm{t}=0$, the production starts and simultaneously supply also beginsandthe production stops at $\mathrm{t}=\mathrm{t}_{1}$ when the maximum inventory level $\mathrm{Q}_{1}$ is reached. In the interval $\left[0, \mathrm{t}_{1}\right]$, before the production stops, the inventory is built up at a rate $\mathrm{k}-\mathrm{D}$ and is depleted at the rate $(\theta-\mathrm{b}+\mathrm{c})$. In the interval $\left[t_{1}, t_{2}\right]$ the inventory is depleted at the rate $D$ and rate $(\theta-b)$. The inventory is finitely decreasing in the time interval $\left[\mathrm{t}_{1}, \mathrm{t}_{2}\right]$ until inventory level reaches zero. It is decided to backlog the demands up to $\mathrm{Q}_{2}$ level which occurs during stock-out time. Thereafter, shortages can occur during the time interval $\left[t_{2}, t_{3}\right]$, and all of the demand during the period $\left[\mathrm{t}_{2}, \mathrm{t}_{3}\right]$ is completely backlogged. Thereafter, production is started at a rate $(1-\mathrm{r})(\mathrm{k}-$ D)so as to clear the backlog, and the inventory level reaches to 0 (i.e. the backlog is cleared) at $\mathrm{t}=\mathrm{T}$.

The pictorial presentation is shown in the Figure - 1 . 


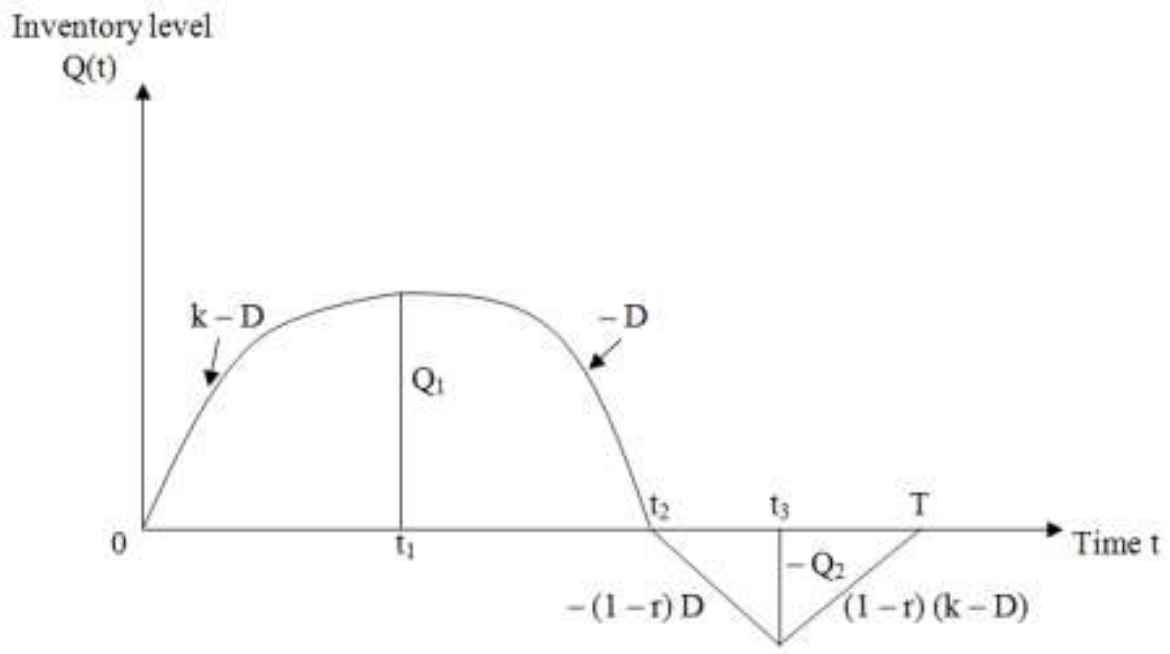

Figure - 1: Graphical presentation of the inventory system

The differential equations which govern the instantaneous state of $\mathrm{Q}(\mathrm{t})$ over the time intervals $\left[0, \mathrm{t}_{1}\right],\left[\mathrm{t}_{1}, \mathrm{t}_{2}\right],\left[\mathrm{t}_{2}\right.$, $\left.t_{3}\right]$ and $\left[t_{3}, T\right]$ are given by

$$
\begin{array}{ll}
\frac{d Q(t)}{d t}+(\theta-b+c) Q(t)=k-(\alpha+\beta t), & \left(0 \leq t \leq t_{1}\right) \\
\frac{d Q(t)}{d t}+(\theta-b) Q(t)=-(\alpha+\beta t), & \left(t_{1} \leq t \leq t_{2}\right) \\
\frac{d Q(t)}{d t}=-(1-r)(\alpha+\beta t), & \left(t_{2} \leq t \leq t_{3}\right) \\
\frac{d Q(t)}{d t}+(1-r) c \cdot Q(t)=(1-r)\{k-(\alpha+\beta t)\}, & \left(t_{3} \leq t \leq T\right)
\end{array}
$$

Under the boundary conditions $\mathrm{Q}(0)=0, \mathrm{Q}\left(\mathrm{t}_{1}\right)=\mathrm{Q}_{1}, \mathrm{Q}\left(\mathrm{t}_{2}\right)=0, \mathrm{Q}\left(\mathrm{t}_{3}\right)=-\mathrm{Q}_{2} \& \mathrm{Q}(\mathrm{T})=0$, the solutions of equations(1) to (4)are given by

$$
\begin{array}{ll}
Q(t)=(k-\alpha) \cdot t & \left(0 \leq t \leq t_{1}\right) \\
Q(t)=-\alpha t+[\alpha(1-t \xi)] t_{2}+[\beta(1-t \xi)] t_{2}^{2} & \left(t_{1} \leq t \leq t_{2}\right) \\
Q(t)=(1-r)\left(\alpha\left(t_{2}-t\right)+\frac{1}{2} \beta\left(t_{2}^{2}-t^{2}\right)\right) & \left(t_{2} \leq t \leq t_{3}\right) \\
Q(t)=(1-r)\left\{\left[\frac{k-\alpha}{\mu}-\beta\left(\frac{t}{\mu}-\frac{1}{\mu^{2}}\right)\right]+(1+\mu T)(1-\mu t)\left[-\frac{k-\alpha}{\mu}+\beta\left(\frac{T}{\mu}-\frac{1}{\mu^{2}}\right)\right]\right\} & \left(t_{3} \leq t \leq T\right)
\end{array}
$$

[Where $\delta=\theta-\mathrm{b}+\mathrm{c}, \xi=\theta-\mathrm{b}$ and $\mu=(1-\mathrm{r})^{\circ} \mathrm{c}$ ]

From (5), $\quad Q\left(t_{1}\right)=Q_{1}=(k-\alpha) \cdot t_{1}$

and from (6), $Q\left(t_{1}\right)=Q_{1}=-\alpha t_{1}+\left[\alpha\left(1-\xi t_{1}\right)\right] t_{2}+\left[\beta\left(1-\xi t_{1}\right)\right] t_{2}^{2}$

Eliminating $\mathrm{Q}\left(\mathrm{t}_{1}\right)$ from equations (9) and (10), we get

$t_{1}=\frac{\left(\alpha+\beta t_{2}\right) t_{2}}{\alpha \xi t_{2}+\beta \xi t_{2}^{2}+k}$ 
Thus, $\mathrm{t}_{1}$ can be written in terms of $\mathrm{t}_{2}$ and so $\mathrm{t}_{1}$ is not a decision variable.

From (7), $\quad Q\left(t_{3}\right)=-Q_{2}=(1-r)\left(\alpha\left(t_{2}-t_{3}\right)+\frac{1}{2} \beta\left(t_{2}^{2}-t_{3}^{2}\right)\right)$

and from (8),

$$
Q\left(t_{3}\right)=-Q_{2}=(1-r)\left\{\begin{array}{l}
{\left[\frac{k-\alpha}{\mu}-\beta\left(\frac{t_{3}}{\mu}-\frac{1}{\mu^{2}}\right)\right]} \\
+(1+\mu T)\left(1-\mu t_{3}\right)\left[-\frac{k-\alpha}{\mu}+\beta\left(\frac{T}{\mu}-\frac{1}{\mu^{2}}\right)\right]
\end{array}\right\}
$$

Eliminating $\mathrm{Q}\left(\mathrm{t}_{3}\right)$ from equations (12) and (13), we get

$$
t_{2}=\frac{1}{\beta}\left\{-\alpha+\sqrt{\alpha^{2}+2 \beta k t_{3}+\beta^{2} t_{3}^{2}+\left[\left(2 T \alpha \beta-2 T \beta k+2 T^{2} \beta^{2}\right)\left(1-\mu t_{3}\right)\right]}\right\}
$$

Thus, $t_{2}$ can be written in terms of $t_{3}$ and so $t_{2}$ is alsonot a decision variable.

\section{Cost Components:}

The total cost per replenishment cycle consists of the following cost components:

\section{1) Ordering Cost $(\mathrm{OC})$}

The ordering cost $\mathrm{OC}$ over the period $[0, \mathrm{~T}]$ is

$\mathrm{OC}=\mathrm{A}($ Fixed $)$

\section{2) Deterioration Cost (DC)}

The deterioration cost DC over the period $\left[0, t_{1}\right]$ and $\left[\mathrm{t}_{3}, \mathrm{~T}\right]$ is

$$
\begin{aligned}
& D C=C_{d} \cdot c\left[\int_{0}^{t_{1}} Q(t) d t+(1-r) \int_{t_{3}}^{T} Q(t) d t\right] \\
& \Rightarrow D C=C_{d} \cdot C\left\{\frac{1}{2}(k-\alpha) t_{1}^{2}+(1-r)\left(\begin{array}{l}
\frac{1}{2}\left[-\frac{(1-r) \beta}{\mu}-(1+T \mu)(1-r)\left(-\frac{k-\alpha}{\mu}+\beta\left(\frac{T}{\mu}-\frac{1}{\mu^{2}}\right)\right)\right. \\
+(1-r)\left(\frac{k-\alpha}{\mu}+\frac{\beta}{\mu^{2}}\right)\left(T-t_{3}\right) \\
+(1+T \mu)(1-r)\left(-\frac{k-\alpha}{\mu}+\beta\left(\frac{T}{\mu}-\frac{1}{\mu^{2}}\right)\right)\left(T-t_{3}\right)
\end{array}\right)\right\}
\end{aligned}
$$

\section{3) Inventory Holding Cost (IHC)}

The inventory holding cost IHC over the period $\left[0, \mathrm{t}_{2}\right]$ is

$$
\begin{aligned}
& I H C=C_{h}\left[\int_{0}^{t_{1}} Q(t) d t+\int_{t_{1}}^{t_{2}} Q(t) d t\right] \\
& \Rightarrow I H C=C_{h}\left[\frac{1}{2}(k-\alpha) t_{1}^{2}-\frac{1}{2}\left(\beta \xi t_{2}^{2}+\alpha \xi t_{2}+\alpha\right)\left(t_{2}^{2}-t_{1}^{2}\right)+\beta t_{2}^{2}\left(t_{2}-t_{1}\right)+\alpha t_{2}\left(t_{2}-t_{1}\right)\right]
\end{aligned}
$$

\section{4) Shortage Cost (SC)}

Demand during the time $\left[\mathrm{t}_{3}, \mathrm{~T}\right]$ is satisfied at a time as the production hasalready started at time $\mathrm{t}=\mathrm{t}_{3}$ and so shortage cost during this interval is not taken into account.

The shortage cost SC over the period $\left[\mathrm{t}_{2}, \mathrm{t}_{3}\right]$ is 


$$
\begin{aligned}
& S C=-C_{S} \int_{t_{2}}^{t_{3}} Q(t) d t \\
& \Rightarrow S C=-C_{S}(1-r)\left[-\frac{1}{6} \beta\left(t_{3}^{3}-t_{2}^{3}\right)-\frac{1}{2} \alpha\left(t_{3}^{2}-t_{2}^{2}\right)+\left(\alpha t_{2}+\frac{1}{2} \beta t_{2}^{2}\right)\left(t_{3}-t_{2}\right)\right]
\end{aligned}
$$

\section{5) Lost Sale Cost (LSC)}

The lost sale cost LSC over the period $\left[t_{2}, t_{3}\right]$ is

$$
\begin{aligned}
& L S C=C_{p} \cdot r \int_{t_{2}}^{t_{3}}(\alpha+\beta t) d t \\
& \Rightarrow L S C=C_{p} r\left(\alpha\left(t_{3}-t_{2}\right)+\frac{1}{2} \beta\left(t_{3}^{2}-t_{2}^{2}\right)\right)
\end{aligned}
$$

\section{6) Purchase Cost (PC)}

The purchase cost $\mathrm{PC}$ over the period $[0, \mathrm{~T}]$ is

$$
\begin{aligned}
& P C=P_{c} \cdot k\left(t_{1}+t_{3}-t_{2}\right) \\
& \left.P C=P_{c} \cdot k\left[\frac{\left(\alpha+\beta t_{2}\right) t_{2}}{\alpha \xi t_{2}+\beta \xi t_{2}^{2}+k}+t_{3}-\frac{1}{\beta}\left\{-\alpha+\sqrt{\alpha^{2}+2 \beta k t_{3}+\beta^{2} t_{3}^{2}+\left[\left(2 T \alpha \beta-2 T \beta k+2 T^{2} \beta^{2}\right)\left(1-\mu t_{3}\right)\right.}\right]\right\}\right]
\end{aligned}
$$

Hence, the total cost per unit time for the time period $[0, \mathrm{~T}]$ is given by

$$
\mathrm{TC}=\frac{1}{\mathrm{~T}}(\mathrm{OC}+\mathrm{DC}+\mathrm{IHC}+\mathrm{SC}+\mathrm{LSC}+\mathrm{PC})
$$

Now, our objective is to determine optimum values $\mathrm{t}_{3}{ }^{*}$ and $\mathrm{T}^{*}$ of $\mathrm{t}_{3}$ and $\mathrm{T}$ respectively to minimize the total cost TC. Using mathematical software, the optimal values $t_{3}{ }^{*}$ and $T^{*}$ can be obtained by solving $\frac{\partial T C}{\partial t_{3}}=0$ and $\frac{\partial \mathrm{TC}}{\partial \mathrm{T}}=0$ which can satisfy the following sufficient conditions:

$$
\left.\begin{array}{l}
{\left[\left(\frac{\partial^{2} \mathrm{TC}}{\partial \mathrm{t}_{3}^{2}}\right)\left(\frac{\partial^{2} \mathrm{TC}}{\partial \mathrm{T}^{2}}\right)-\left(\frac{\partial^{2} \mathrm{TC}}{\partial \mathrm{t}_{3} \partial \mathrm{T}}\right)^{2}\right]_{\mathrm{t}_{3}=\mathrm{t}_{3}^{*}, \mathrm{~T}=\mathrm{T}^{*}}>0} \\
{\left[\left(\frac{\partial^{2} \mathrm{TC}}{\partial \mathrm{t}_{3}^{2}}\right)\right]_{\mathrm{t}_{3}=\mathrm{t}_{3}^{*}, \mathrm{~T}=\mathrm{T}^{*}}>0}
\end{array}\right\}
$$




\section{Numerical Example}

To illustrate the proposed model, an inventory system with the following hypothetical values is considered. By taking $\alpha=40, \beta=0.001, \mathrm{C}_{\mathrm{h}}=0.8, \mathrm{C}_{\mathrm{d}}=2, \mathrm{C}_{\mathrm{p}}=5, \mathrm{Cs}=2, \theta=0.01, \mathrm{~b}=0.005, \mathrm{c}=0.06, \mathrm{r}=0.09$, $\mathrm{k}=60$ and $\mathrm{A}=300$ (with appropriate units), optimal values of $\mathrm{t}_{3}$ and $\mathrm{T}$ are $\mathrm{t}_{3} *=8.664682800, \mathrm{~T}^{*}=25.29411443$ units and the optimal total cost per unit time $\mathrm{TC}=126.5618193$ units.

\section{Sensitivity Analysis}

Sensitivity analysis depicts the extent to which the optimal solution of the model is affected by the changes in its input parameter values. Here, we study the sensitivity for the cycle length $\mathrm{T}$ and total cost per time unit TC with respect to the changes in the values of the parameters $\alpha, \beta, \mathrm{C}_{\mathrm{h}}, \mathrm{C}_{\mathrm{d}}, \mathrm{Cp}, \mathrm{Cs}, \theta, \mathrm{b}, \mathrm{c}, \mathrm{r}, \mathrm{k}$ and $\mathrm{A}$. The sensitivity analysis is performed by considering different values in each one of the above parameters keeping all other parameters as fixed. The results are presented in the Table.

Table:Partial Sensitivity Analysis

\begin{tabular}{|c|c|c|c|c|c|}
\hline Parameter & $\%$ & $t_{3}$ & $\mathrm{~T}$ & TC & $\%$ change in $\mathrm{TC}$ \\
\hline \multirow{4}{*}{$\alpha$} & -10 & 9.314694607 & 24.27554607 & 129.6847228 & 2.47 \\
\hline & -05 & 9.060134527 & 24.87171030 & 128.6346419 & 1.64 \\
\hline & +05 & 9.575232049 & 22.83983430 & 129.1252431 & 2.03 \\
\hline & +10 & 6.795258895 & 24.21483912 & 118.1465409 & -6.65 \\
\hline \multirow{4}{*}{$\beta$} & -10 & 8.665547815 & 25.29378321 & 126.5682307 & 0.0051 \\
\hline & -05 & 8.665114980 & 25.29398694 & 126.5649983 & 0.0025 \\
\hline & +05 & 8.664278055 & 25.29435706 & 126.5586179 & -0.0025 \\
\hline & +10 & 8.663797766 & 25.29438876 & 126.5554025 & -0.0051 \\
\hline \multirow{4}{*}{$\mathrm{C}_{\mathrm{h}}$} & -10 & 8.826234244 & 25.52562423 & 125.6524724 & -0.72 \\
\hline & -05 & 8.746522473 & 25.41424588 & 126.1022482 & -0.36 \\
\hline & +05 & 8.594913624 & 25.20151358 & 126.9561036 & 0.31 \\
\hline & +10 & 8.526715876 & 25.10923951 & 127.3363820 & 0.61 \\
\hline \multirow{4}{*}{$\mathrm{C}_{\mathrm{d}}$} & -10 & 8.978771732 & 26.59655084 & 124.3731096 & -1.73 \\
\hline & -05 & 8.818701486 & 25.92256960 & 125.5009322 & -0.84 \\
\hline & +05 & 8.516208777 & 24.70602428 & 127.5620582 & 0.79 \\
\hline & +10 & 8.372836499 & 24.15393468 & 128.5069043 & 1.54 \\
\hline \multirow{4}{*}{$\mathrm{C}_{\mathrm{p}}$} & -10 & 8.489861457 & 24.42544911 & 118.6665614 & -6.24 \\
\hline & -05 & 8.578163592 & 24.86306834 & 122.6303315 & -3.11 \\
\hline & +05 & 8.785634529 & 25.70576324 & 131.7545938 & 4.10 \\
\hline & +10 & 8.905227459 & 26.12744231 & 135.8244732 & 7.32 \\
\hline \multirow{4}{*}{ Cs } & -10 & 8.462429432 & 25.02492440 & 125.7057239 & -0.68 \\
\hline & -05 & 8.558090273 & 25.15990219 & 126.1572357 & -0.32 \\
\hline & +05 & 8.763050331 & 25.41798970 & 126.9349913 & 0.29 \\
\hline & +10 & 8.854080565 & 25.53263895 & 127.2801727 & 0.57 \\
\hline \multirow{4}{*}{$\theta$} & -10 & 8.599404426 & 25.19846964 & 126.8592190 & 0.23 \\
\hline & -05 & 8.631745684 & 25.24597991 & 126.7118618 & 0.12 \\
\hline & +05 & 8.698239772 & 25.34289637 & 126.4091007 & -0.12 \\
\hline & +10 & 8.732442178 & 25.39235043 & 126.2535609 & -0.24 \\
\hline \multirow{4}{*}{$\mathrm{b}$} & -10 & 8.698239772 & 25.34289637 & 126.4091007 & -0.12 \\
\hline & -05 & 8.681382244 & 25.31842297 & 126.4858711 & -0.06 \\
\hline & +05 & 8.648138296 & 25.26996772 & 126.6371650 & 0.06 \\
\hline & +10 & 8.631745684 & 25.24597991 & 126.7118618 & 0.12 \\
\hline \multirow{4}{*}{$\mathrm{c}$} & -10 & 9.662043332 & 27.92445113 & 126.9326540 & 0.29 \\
\hline & -05 & 9.136330092 & 26.53887670 & 126.7116551 & 0.12 \\
\hline & +05 & 8.239133850 & 24.16944489 & 126.4733083 & -0.07 \\
\hline & +10 & 7.853216402 & 23.14806098 & 126.4381012 & -0.10 \\
\hline \multirow{4}{*}{$\mathrm{r}$} & -10 & 8.544024187 & 24.92631588 & 126.6369017 & 0.06 \\
\hline & -05 & 8.604072005 & 25.10915505 & 126.5995069 & 0.03 \\
\hline & +05 & 8.725865710 & 25.48123189 & 126.5237261 & -0.03 \\
\hline & +10 & 8.787630053 & 25.67054617 & 126.4853834 & -0.06 \\
\hline \multirow{4}{*}{$\mathrm{k}$} & -10 & 8.702424294 & 24.40578093 & 103.6354453 & -18.11 \\
\hline & -05 & 9.227624464 & 24.54624572 & 116.6792374 & -07.81 \\
\hline & +05 & 9.017541849 & 24.77252051 & 134.3868513 & 06.18 \\
\hline & +10 & 9.227672496 & 24.16722090 & 141.2883776 & 11.64 \\
\hline \multirow{4}{*}{ A } & -10 & 8.559347452 & 24.90282843 & 126.5105357 & -0.04 \\
\hline & -05 & 8.615342424 & 25.11355351 & 126.0267357 & -0.42 \\
\hline & +05 & 8.698004189 & 25.43623237 & 127.1532333 & 0.47 \\
\hline & +10 & 8.730462016 & 25.57552735 & 127.7412747 & 0.93 \\
\hline
\end{tabular}




\section{Graphical Presentation}

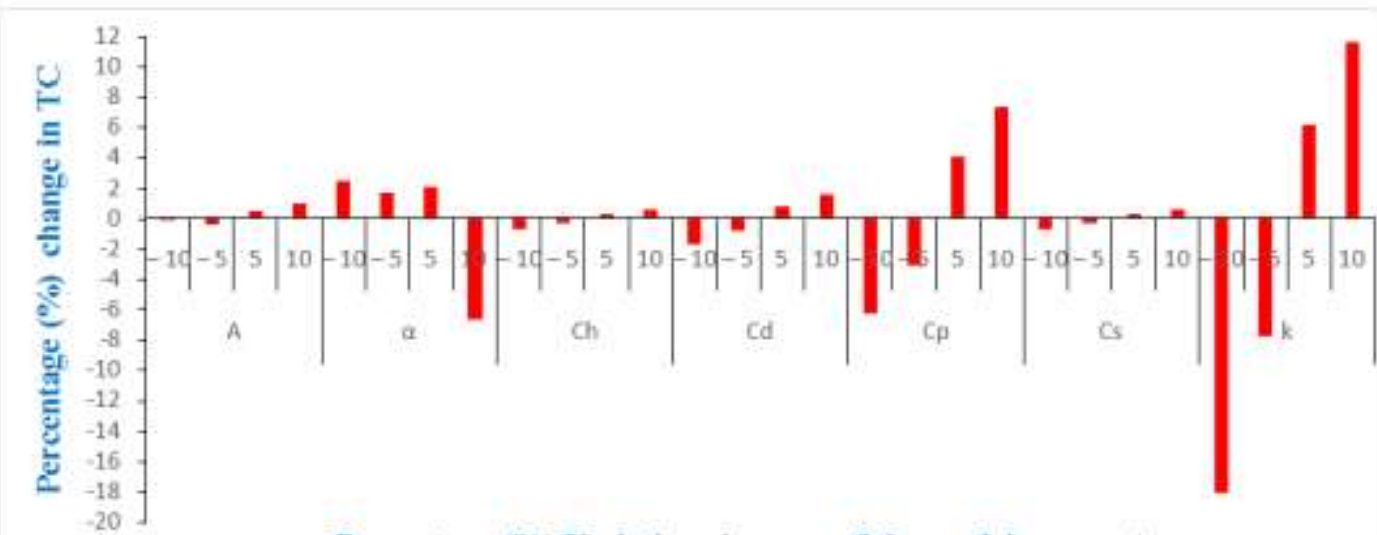

Percentage $(\%)$ Variations in some of the model parameters

Figure - 2

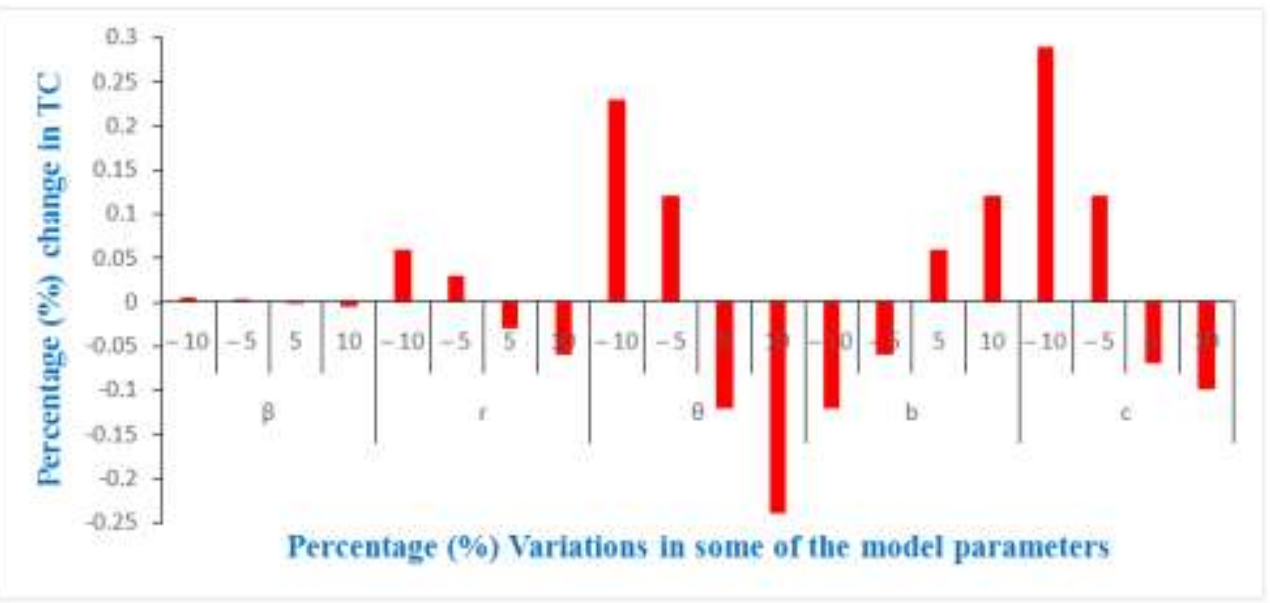

Figure $-\mathbf{3}$

\section{Conclusions}

$>$ From the Tablewe can conclude that TC is highly sensitive to the change in $\mathrm{C}_{\mathrm{p}}$ and $\mathrm{k}$, moderately sensitive to the change in $\alpha$ and $C_{d}$ and less sensitive to change in $\beta, C_{h}, C s, \theta, b, c, A$ and $r$.

$>$ It is observed from Figure $\mathbf{- 2}$ that the effect of increase or decrease in the values of $\alpha$ does not affectthe total cost TC much.

$>$ It is observed fromFigure -2 that when the values of $A, C_{h}, C_{d}, C p$ s and $k$ increase simultaneously the average total cost TC also increases.

$>$ It is observed from Figure $-\mathbf{3}$ that when the values of $\mathrm{b}$ increase then TC also increases and when the values of $\beta, \theta, \mathrm{c}$ and $\mathrm{r}$ increase, TC decreases.

\section{References}

[1] Bhojak, A., Gothi, U.B. A note on an order-level model for a system with constant rate of deterioration. International Journal of Management and Social Science Research Review, 1(2), 2016, 85-98p.

[2] Chen S. J., Chen S. P., and Liu X. B., A production inventory model for deteriorating items, Journal of Zhaoqing University, Vol. 23, No. 2, 2002, pp. 66-68.

[3] Chatterji, D. A. and Gothi, U. B., Three-parametric Weibully deteriorated EOQ model with price dependent demand and shortages under fully backlogged condition, International Journal of Innovative Research in Science, Engineering and Technology, Vol. 4, Issue 12, 2015, 12710-12720.

[4] Datta, T. K. and Pal, A. K. Order level inventory system with power demand pattern for items with variable rate of deterioration. Ind Journal of Pure \& Applied. Maths, 19 (11),1988, 1043-1053. 
[5] Ghare, P. M., and Schrader, G.F., A model for an exponentially decaying inventory, Journal of Industrial Engineering, 14, pp. 1963, $238-243$

[6] Goyal and Giri, The production-inventory problem of a product with time varying demand, production anddeterioration rates, European Journal of Operational Research, Vol. 147, 2003, pp. 549-557.

[7] Harris F.W., Operations and cost, 1915, Shaw Company, Chicago: A. W.

[8] Jain, M. and Sharma, G. C., Rathore, S., Economic order quantity model with shortages and stock dependent demand for deteriorating items, IJE Transactions A: Basics, Vol. 20(2), 2007, pp. 159-168.

[9] Kirtan Parmar and Gothi U. B.,An EPQ model of deteriorating items using three parameter Weibull distribution with constant production rate and time varying holding cost, International Journal of Science, Engineering and Technology Research, Vol. 4, Issue 2, 2015, pp. $0409-416$.

[10] Koh, S.G., Hwang, H., Sohn, K.I., \& Ko, C.S. An optimal ordering and recovery policy for reusable items, Computers \& Industrial Engineering, 43, 2002, 59-73.

[11] Mabini, M.C., Pintelon, L.M., \& Gelders, L.F. EOQ type formulation for controlling repairable inventories, International Journal of Production Economics, 28, 1992, 21-33.

[12] Manna and Chaudhuri, An EOQ model with ramp type demand rate, time dependent deterioration rate, Unit production cost and shortages, European Journal of Operational Research, Vol.171, 2006, pp. 557-566.

[13] Manna, S. K. and Chiang, C., Economic production quantity models for deteriorating item with ramp type demand", International Journal Operation Research, Vol. 7, 2010, pp. 429 - 444.

[14] Mandal, B. N. and Ghosh, A. K., A note on an inventory model with different demand rates during stock in and stock and period. Int. Journal of Mgt. \& Syst, 7 (1), 1991, 33-36.

[15] Mandal, B. N. and Pal A. K., Order level inventory system for perishable items with power demand pattern Int. Journal of Mgt.\& Syst. 16 (3), 2000, 259-276.

[16] Raman Patel, Production inventory model for Weibull deteriorating items with price and quantity dependent demand, time varying holding cost and shortages, Indian Journal of Applied Research, Vol. 4, Issue 1, 2014

[17] Roy, T. and Chaudhary, K. S., A production inventory model under stock dependent demand, Weibull distribution deterioration and shortages, International Transactions in Operations Research, Vol. 16, 2009, pp. 325-346.

[18] Sana, S. Goyal, S. K. and Chaudhuri, K. S., A production - inventory model for a deteriorating item with trended demand and shortages, European Journal of Operational Research, Vol. 157, 2004, 357-371.

[19] Schrady, D.A. A Deterministic inventory model for repairable items, Naval Research Logistics Quarterly, 14, 1967, $391-398$.

[20] Skouri, K and Papachristos, S., Optimal stopping and restarting production times for an EOQ model with deteriorating items and time-dependent partial backlogging," International Journal of Production Economics, Vol. 81-82, 2003 , pp. 525-531.

[21] Teng, J. T., A deterministic replenishment model with linear trend in demand. Opns. Res. Lett. 19,1996,33-41.

[22] Teng, J.T. and Chang, H.T., Economic production quantity model for deteriorating items with price and stock dependent demand; Computers and Oper. Res., Vol. 32, 2005, pp. 279-308.

[23] Thierry, M.C., Salomon, M., Van Numen, J.,\& Van Wassenhove, L. Strategy issues in product recovery management, California Management Review, 37(2), 1995, 114-135.

[24] Wilson R.H., A scientific routine for stock control, Hary Bus Rev 13, 1934, pp. 116 - 128

[25] Whitin, T.M., The theory of Inventory Management, $2^{\text {nd }}$ edition, Princeton University Press, Princeton, New Jersey, 1957 , pp. 62 72.

[26] Yadav, R. and Rajeev Kumar, An inventory model for deteriorating and repairable items with linear demand, vol. 10 (6), 2014,01 06. 